\title{
SHAYKH WALTYULLĀH AL-DIHLAWI DAN KONSEP-KONSEP KUNCI DALAM PENAFSIRAN ALQURAN
}

\author{
Abdul Djalal \\ Universitas Islam Negeri Sunan Ampel Surabaya \\ abduldjalal81@gmail.com
}

\begin{abstract}
This article attempts to explore the thought of Shaykh Waliyullāh al-Dihlawi on the Qur'an and key concepts of the Qur'anic science. By using historical approach and content analysis method, I argue that al-Dihlawi is a Muslim reformist whose thought on understanding the Qur'an is rarely discussed by Indonesian Muslim scholars. He is expert not only in the field of Islamic law, mysticism, and thought, but also in the field of Qur'anic exegesis. His thought and ideas have been referred to and followed by Muslims of Bahrevi and Deoband and has inspired the ideas of neoMu'tazilah in India. Through his rational way of thinking, he offers a new light of understanding the Qur'an through historical perspective with regard to the concept of asbāb al-nuzull, al-naskh, and the Israelite tales of previous community. Beside the historical consciousness, al-Dihlawi requires also a necessity for understanding the universal message behind the text. These were among the reformist thoughts of al-Dihlawi which arose in the desert of the Muslim traditional conviction.
\end{abstract}

Keywords: Al-Dihlawi, The Qur'an, Concepts of Qur'anic Interpretation

\begin{abstract}
Abstrak: Artikel ini mengeksplorasi pemikiran Shaykh Waliyullāh al-Dihlawi tentang Alquran dan konsep-konsep kunci dari ilmu Alquran. Dengan menggunakan pendekatan historis dan metode analisis isi, penulis berargumen bahwa al-Dihlawi adalah seorang reformis Muslim yang pemikirannya tentang kajian Alquran kurang mendapat perhatian dari para sarjana Muslim Indonesia. Padahal, al-Dihlawi tidak hanya tidak hanya ahli di bidang hukum Islam, mistisisme, dan pemikiran keislaman, namun juga di bidang tafsir Alquran. Pemikiran dan idenya banyak dirujuk dan diikuti oleh Muslim Bahrevi dan Deoband dan telah mengilhami ide-ide neo-Muktazilah di India. Melalui cara berpikirnya yang rasional, ia menawarkan cara baru untuk memahami Alquran melalui perspektif sejarah dengna memberi

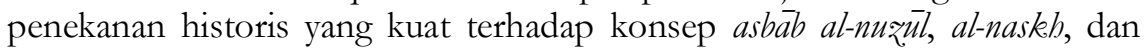
isra'itiyat. Selain kesadaran historis, al-Dihlawi juga menuntut perlunya memahami pesan universal di balik teks. Pemikiran tersebut merupakan sebuah gagasan reformis al-Dihlawi yang muncul di tengah gersangnya pemahaman Muslim tradisional.
\end{abstract}

Kata kunci: al-Dihlawi, Alquran, Konsep Kunci Interpretasi Alquran 


\section{Pendahuluan}

Reputasi Shaykh Waliyullāh al-Dihlawi sebagai perintis jalan baru bagi pemikiran dan sistem ajaran Islam telah diakui oleh para pemerhati pemikiran keislaman, baik dari kalangan insider maupun outsider. Iqbal, misalnya, mengakui al-Dihlawi sebagai orang pertama yang menetapkan semangat baru dalam dirinya, yaitu semangat untuk memikirkan kembali keseluruhan sistem ajaran Islam, tanpa memutuskan sama sekali keterkaitannya dengan masa lalu. ${ }^{1}$ Lebih khusus lagi J.M.S Baljon mengakui al-Dihlawi sebagai a precursor of Modern Muslim Koran Interpretation. ${ }^{2}$ Dalam sejarah penafsiran Alquran di anak benua India, al-Dihlawi diakui sebagai orang pertama yang melakukan pembaharuan metodologi tafsir Alquran. ${ }^{3}$

Pengakuan demi pengakuan tersebut wajar diberikan kepada alDihlawi karena sumbangsihnya yang besar bagi dunia pemikiran Islam modern. Kitab Hujjat Allāh al-Bälighah, misalnya, yang merupakan bukti kontribusinya, ${ }^{4}$ mendapat respon positif yang sangat luas di Timur Tengah dan bahkan dalam waktu lama menjadi kitab standar di Al-Azhar University, Kairo, Mesir. ${ }^{5}$ Di samping kitab tersebut, alDihlawi dalam Qur'anic Studies telah menyumbangkan beberapa karya penting, di antaranya adalah Al-Fawz al-Kabir fì Ușil al-Tafsir, yang menyajikan gagasan al-Dihlawi tentang prinsip-prinsip memahami Alquran, Fatḥ al-Raḅmān fì Tafsìr al-Qur'an, terjemah Alquran ke dalam bahasa Persia yang mendapat kritik keras pada saat itu, Fath al-Munir, kitab tafsir yang mengkaji kata-kata asing dalam Alquran, dan Zahrawayn, kitab tafsir surat al-Baqarah dan Āli 'Imrān. Kitab-kitab tersebut, terutama dua yang pertama telah mempengaruhi atau setidaknya telah memberi inspirasi bagi munculnya gagasan-gagasan tentang Alquran dan penafsirannya di abad modern.

\footnotetext{
${ }^{1}$ M. Iqbal, The Reontruction of Religious Thought in Islam (Lahore: Shaykh M. Ashraf, 1962), 7.

2 J.M.S Baljon, Modern Muslim Koran Interpretation (1880-1960) (Leiden: E.J. Brill, 1963), 2.

3 Al-Sayyid Murtada Husayn al-Ṣadr al-Fạdil, "Beberapa Metodologi Tafsir Alquran di Anak Benua India," terj. Husain al-Kaff, dalam Jurnal al-Hikmah, vol. VI, no. XIV (1995), 11.

${ }^{4}$ Lihat pengakuan Smith dalam W.C. Smith, Islam ini Modern History (New York: Princeton University Press, 1957), 51.

${ }^{5}$ Maryam Jameelah, Islam in Theory and Paractice (Delhi: Taj Company, 1983), 156.
} 
Namun demikian, patut disayangkan kalau kemudian pemikiran al-Dihlawi tentang Alquran dan penafsirannya kurang dikenal secara luas di Indonesia, baik di dunia akademik maupun di pesantren. Padahal jika ditarik sejarah ulama di Indonesia dan geneologi pemikiran Islam Nusantara, akan ditemukan benang merah yang menghubungkan mereka dengan ulama di kawasan India, termasuk alDihlawi. ${ }^{6}$ Oleh karena itu, penulis melihat pentingnya mengkaji pemikiran al-Dihlawi tentang Alquran dan penafsirannya dengan memaparkan gagasan-gagasannya dan sejauh mana pemikirannya tersebut mempengaruhi atau setidaknya mengilhami generasi-generasi sesudahnya.

\section{Sejarah Kehidupan Waliyullāh al-Dihlawi}

Nama lengkap al-Dihlawi adalah Quṭb al-Dīn Aḥmad b. 'Abd alRaḥmān, namun lebih dikenal dengan sebutan Shaykh Waliyullāh alDihlawi. Dia dilahirkan pada hari Rabu, 4 Syawwal 1114/1702, di Delhi, ${ }^{7}$ dan meninggal pada hari Sabtu sore, 29 Muharram 1176/1762, pada usia 61 tahun, di tempat kelahirannya. ${ }^{8}$ Konon genealogi keturunan al-Dihlawi berhubungan dengan nasab khalifah kedua, 'Umar b. Khattab, dari sisi ayah, dan berhubungan nasab dengan khalifah keempat, 'Ali b. Abi Ṭa lib, dari pihak ibu. Dengan demikian, kakek al-Dihlawi berasal dari Arab yang diperkirakan pindah dari Arab sekitar abad ke-13 Masehi dan pertama kali menetap di kota Rohtak, sebuah kota yang terletak antara Hansi dan Delhi. ${ }^{9}$ Al-Dihlawi lahir di sebuah desa kecil, Pulth. Desa ini memang sudah lama menjadi pusat kajian keislaman bagi para ulama. Sejak kecil al-Dihlawi sudah menampakkan tanda-tanda yang menunjukkan bahwa di masa tuaya akan menjadi ulama besar. ${ }^{10}$

Al-Dihlawi mendapatkan pendidikan hampir di semua bidang ilmu dari Ayahnya. Menjelang umur tujuh tahun, dia telah selesai membaca Alquran dan menjelang umur 10 tahun sudah mempelajari

\footnotetext{
6 Azyumardi Azra, Jaringan Ulama' Timur Tengah dan Kepulauan Nusantara, Mencari Akar-akar Pembaharuan Pemikiran Islam di Indonesia (Bandung: Mizan, 1995), 141.

${ }^{7}$ G.N. Jalbani, Life of Shaykh W aliyullāh (Delhi: Idarah-1 Delli, 1980), 1.

${ }^{8}$ Ibid.

9 J.M.S. Baljon, Religion and Thoutght of Shaykh Waliyullāh al-Diblawì (Leiden: E.J. Brill, 1963), 1.

10 Ibid., 4-5.
} 
ilmu bahasa Arab karya Ibn al-Hạjib, ${ }^{11}$ sehingga pada usia ini dia telah mampu belajar kitab-kitab yang berbahasa Arab dan Persia sendiri. Disamping belajar ilmu-ilmu agama, dia juga belajar ilmu-ilmu lain, seperti matematika dan kedokteran. ${ }^{12}$ Ketika masih berumur 15 tahun, dua tahun sebelum ayahnya meninggal, dia masuk dalam lingkaran tarekat Qadariyah, Chistiyah, dan Naqsabandiyah atas saran ayahnya. ${ }^{13}$ Pada usia ini pula al-Dihlawi telah diberi tanggung jawab menjalankan roda pendidikan di lembaga pendidikan milik ayahnya.

Al-Dihlawi telah tamat mempelajari kitab Al-jur' al-Latîf Mishkeat al-Masăliḩ karya Khațīb 'Umar al-Ṭibrizi pada sekitar umur 15 tahun. Kemudian, orang tuanya mendorong al-Dihlawi untuk mengkaji kitab

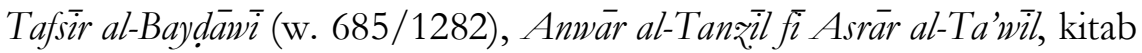
tafsir yang lebih didasarkan kepada kitab Tafsir al-Kashshäf karya alZamakhshari. Sebelum selesai mempelajari kitab ini, dia telah diberi izin oleh orang tuanya untuk mengajarkan kepada orang lain. Kemudian, dalam pengawasan ayahnya, dia mengkaji kitab Șahịh alBukhärì, karya al-Imam al-Bukhäri, Shamà'il al-Nabì, karya al-Imām alTirmidhi, Madärij al-Tan₹īil wa Haqà'iq al-Ta'wīl, karya Hāfiz al-Dīn alNasafi (w. 710/1311), yang lebih dikenal dengan nama Tafsir alNasafi. ${ }^{14}$

Dalam bidang ilmu fiqih, al-Dihlawi mempelajari Sharb al-

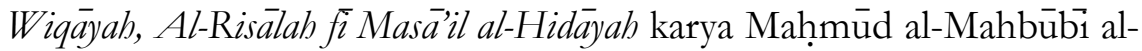
ḤAnafí (w. 800/1397) dan Hidāah fí al-Furū' karya Burhān al-Din alMarginani al-Hanafí (w. 592/1196). sedangkan dalam bidang ilmu usul fiqh, al-Dihlawi mempelajari kitab Al-Husayni karya Hiisān al-Dīn al-Akhsikarti, kitab Tawdīh karya 'Ubayd Allāh al-Bukhāri (w, 747/1346) dan kitab Talwīh karya al-Taftazāni (w. 793/1391). ${ }^{15}$ Pada akhirnya, al-Dihlawi memiliki standar yang cukup untuk disebut sebagai fuqahà' (ahli fikih) disebabkan penguasaannya terhadap pemikiran para imam mazhab, terutama empat imam mazhab, Imam

\footnotetext{
11 Ibid., 3.

12 'Abd al-Haqq al-Ansari, Shaykh W aliyullāh Attemps to Revise Wabdah al-Wujud (t.tp.: t.p., 1988), 199.

13 Ibid., 2-4.

${ }^{14}$ G.N. Jalbani, Life of Shaykh Wa Tiyullāh, 9.

15 Ibid., 10.
} 
Abū Hanīifah, Imam Māilik, Imam al-Shāfīīi, dan Imam Ahmad b. Hanbal. ${ }^{16}$

Al-Dihlawi berangkat ke Mekkah pada bulan Rabi' al-Thāni 1143/21 Oktober 1730. Menurut putranya, 'Abd al-'Aziz, dia menetap di Hijaz selama 14 bulan. Selama di Mekkah, dia belajar Al-Muwatta' karya Imām Mālik kepada Muḥammad Wafdullāh al-Mālikìi. Dia juga belajar hadis kepada Taj al-Din al-Qalāi (w. 1734), putra dari Ibrāhim al-Kurani (w. 1690). Sedangkan di Madinah, dia belajar tasawuf. ${ }^{17}$ Setelah kembali ke tanah airnya, dia mengkosentrasikan diri pada pendidikan di Madrasah dan menulis.

Namun demikian, dalam pandangan Mahmasani, al-Dihlawi selama di tanah suci Mekkah juga menyerap ide-ide Wahabisme. Oleh karena itu, ia menganggap al-Dihlawi sebagai seorang tokoh penyebar Wahabi di India, dikarenakan, menurutnya, ide-ide pembaharuan alDihlawi tidak lepas dari pemikiran Wahabi. ${ }^{18}$

Al-Dihlawi merupakan seorang pemikir yang sangat produktif. Dia meninggalkan banyak karya tulis yang bisa dibaca hingga saat ini. K. Hermansen, misalnya, mencatat sekitar tiga puluh karya al-Dihlawi dalam berbagai bidang ilmu. ${ }^{19}$ Beberapa karya tersebut menjadi sumber primer tulisan ini, seperti Huijat Allāh al-Bälighah, Al-Fawz al-

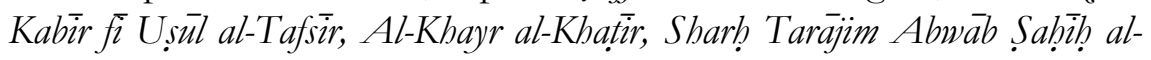
Bukbärì, Kälimät Tayyibāt, dan lain-lain.

Terdapat dua alasan yang menjadikan al-Dihlawi memiliki pemikiran yang maju dan berkembang. Pertama, cakupan ilmunya yang luas dalam berbagai bidang ilmu, seperti tafsir, hadis, fiqih, akhlaq, ilmu kalam, dan filsafat. Kedua, Elaborasinya yang sangat mendalam terhadap berbagai bidang ilmu tersebut. ${ }^{20}$

\section{Ide Pembaharuan Waliyullāh al-Dihlawi}

Al-Dihlawi adalah orang India pertama yang secara terus menerus mengajak untuk kembali kepada Alquran dan Hadis Nabi. Dia senantiasa menanamkan ajaran bahwa hanya Alquran dan Hadis Nabi

\footnotetext{
16 Ibid., 72.

17 Baljon, Religion, 5.

18 Ṣuḅ̣i Maḥmasāni, Tadhkirat min Mālik al-Sunbin (Bairut: Dar al-'Ilm al-Malayin, 1979), 160.

19 Marcea K. Hermansen, Shaykh Waliyullāh of Delhi's al-Hujjatullah al-Bälighah (Leiden: E.J. Brill, 1886), 479-480.

${ }^{20}$ Baljon, Religion, 8.
} 
yang menjadi rujukan dalam menyelesaikan masalah yang dihadapi. Upaya al-Dihlawi ini berakibat dia dituduh kafir oleh masyarakat pada masanya yang masih beranggapan bahwa orang menerjemahkan Alquran dengan bahasa asing selain bahasa Arab sebagai pelaku dosa besar yang hukumannya adalah hukuman mati.21 Bukan hanya memperbaharui sistematika penafsiran Alquran di India, tetapi alDihlawi juga memperbaharui metode dan pendekatan kajian keislaman di sana. Rekonsiliasi berbagai perbedaan adalah pendekatan yang dia gunakan untuk memperbaharui pemikiran Islam pada saat itu. 22

Dalam bidang fiqih, misalnya, al-Dihlawi tidak senang dengan sikap yang meyakini imam mazhab secara fanatik. Dia memperlakukan para imam mazhab secara seimbang. Dia keluar dari sesuatu yang ternyata terdapat perbedaan di antara mereka. Ketika ada perbedaan antara mazhab ḤAnafí dan mazhab al-Shāfi $\bar{i}$, kedua mazhab yang banyak dianut orang pada saat itu, maka menurutnya, diselesaikan dengan merujuk pada kitab Al-Munatța' Imam Māilk, karena kitab ini, baginya, berisi rekaman Nabi yang paling otentik. Kalau pertentangan tersebut belum bisa diselesaikan dengan cara tersebut, maka diselesaikan dengan merujuk kepada hadis Nabi yang sahih. 23

Dalam bidang tasawuf, al-Dihlawi berpandangan bahwa atribut yang terdapat pada orang sufi merupakan atribut yang baik dan menguntungkan. Menurutnya, saying sekali dalam realitas dan praktik pada umumnya ajaran sufi tidak dilaksanakan sesuai dengan ajaran Islam yang sebenarnya. ${ }^{24}$ Dalam titik ini al-Dihlawi berusaha merekonsiliasikan perbedaan yang terjadi di dunia tasawuf. Sementara, dia sendiri menekankan pada transendensi Tuhan melalui konsep Waḅdat al-Shubüd, dan pada saat yang sama dia juga mengakui kesatuan wujud (Wahdat al-Wujüd). ${ }^{25}$

Al-Dihlawi sangat gigih mempertahankan keunggulan akal dan pentingnya ijtihad. Dalam Hujjat Allăh al-Bälighah, dia membahas secara rinci keunggulan akal atas seluruh indra manusia lainnya. Dengan tajam dia mengecam orang-orang yang berpendapat bahwa

21 Jalbani, Life of Shaykh Waliyullāh, 52.

22 Azra, Jaringan Ulama', 142.

${ }^{23}$ Jalbani, Life of Shaykh Waliyullāh, 56.

${ }^{24}$ Ibid., 57.

25 Azra, Jaringan Ulama', 143. 
aturan-aturan syariah tidak memiliki dasar rasional. Dia tidak mau menerima pendapat bahwa syariah dipatuhi karena semata-mata perintah Allah. Menurut pendapatnya, akal manusia mampu memahami kebaikan dalam perintah Allah dan karenanya akal manusia dapat mengetahui keuntungan dalam perintah tersebut, jika dipatuhi. Dengan tekanannya pada keunggulan akal, tidak mengherankan kalau kemudian dia mengecam keras taqlid buta, sebab hal itu hanya akan menimbulkan kemunduran Islam.26 Atas dasar pandangannya tersebut, al-Dihlawi, sebagaimana dinyatakan oleh Ibrāhim al-Kurani, dituduh mempunyai kecenderungan Muktazilah. Sedangkan menurut Aziz Ahmad, aspek pendapat al-Dihlawi tersebut kemudian mengilhami rumusan modernisme neo-Muktazilah Sayyid Aḥmad Khān pada masa berikutnya. ${ }^{27}$

Pengaruh pembaharuan al-Dihlawi selanjutnya dapat dilihat dalam sejarah Islam, terutama di Anak Benua India. Empat gerakan pembaharuan Islam di Anak Benua India mengaitkan diri mereka dengan al-Dihlawi dan masing-masing mengambil satu aspek dari ajaran-ajarannya. Ajaran mengenai pentingnya tasawuf, misalnya, diikuti oleh kaum Bahrevi. Filsafat hukumnya menjadi sumber ilham bagi kaum Deobandi atau tekanannya pada hadis atas fiqih menjadi dasar bagi para ahli hadis. Rasionalismenya merupakan benih bagi kaum modernis neo-Muktazilah India. ${ }^{28}$

\section{Alquran Dalam Perspektof Shaykh Waliyullāh al-Dihlawi}

Sebagaimana ulama muslim yang lain, dalam pandangan alDihlawi, Alquran merupakan kalam Allah yang diwahyukan secara verbal (bukan hanya ide atau konsep) kepada Nabi Muhammad. Hal ini perlu ditegaskan sebelum melihat lebih jauh konsep-konsep alDihlawi yang lain tentang Alquran, karena persoalan tersebut sempat menjadi perdebatan di dunia akademik. Sayyid Aḥmad Khān, misalnya, setelah mengkaji Al-Tafbimât al-Ilabijyat al-Dihlawi, berkesimpulan bahwa, bagi al-Dihlawi, pewahyuan Alquran terbatas

\footnotetext{
26 Shaykh WaTiyullāh al-Dihlawi, Huijat Allāh al-Bälighah, 176.

27 Aziz Ahmad, Studies in Islamic Culture in The Indian Environment (Oxford: Oxford Univercity Press, 1966), 205.

28 Azra, Jaringan Ulama', 144.
} 
pada maknanya saja, sedangkan lafalnya dari Nabi sendiri. ${ }^{29}$ Kesan yang sama ditangkap oleh Fazlur Rahman dari kitab Sataat-nya alDihlawi. ${ }^{30}$

Dengan bacaan yang serupa, Baljon menganggap bahwa kesimpulan Sayyid Aḥmad Khān di atas, begitu juga kesan yang ditangkap oleh Fazlur Rahman, merupakan sebuah kesalahan memahami (misunderstanding). Menurut Baljon, dalam perspektif alDihlawi, bentuk verbal ayat-ayat Alquran bukanlah prestasi Nabi Muhammad. ${ }^{31}$ Pandangan yang terakhir ini diperkuat oleh pernyataan al-Dihlawi dalam Sharḥ Tarajim sebagai berikut:

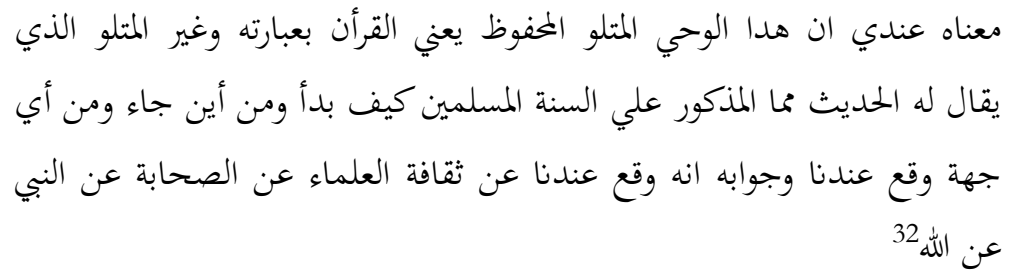

Disamping itu, lima aspek kemukjizatan Alquran, keindahan gaya bahasa, penyampaian kisah-kisah, hukum dan agama-agama terdahulu, pemberitahuan hal-hal yang akan terjadi, serta ketinggian sastra dan rahasia-rahasia syariah, yang dikemukakan oleh al-Dihlawi, dapat membantu membenarkan pandangan Baljon di atas. ${ }^{33}$

Dalam beberapa kitabnya, al-Dihlawi menguraikan pandangannya mengenai asal-usul Alquran. Pertama-tama, menurutnya, Allah menampakkan kehendaknya dengan penampakan yang sangat jelas (tajalli a'zam) bagaikan penampakan cahaya matahari. Di sini berbagai bentuk bercampur jadi satu. Setelah Nabi Muhammad dikirim ke dunia, baru kemudian kehendaknya tersebut dibungkus dengan bahasa Arab. Gaya dan sastra bahasa Arab, bentuk ayat dan surat Alquran bercampur dalam pikiran Nabi Muhammad dengan bantuan otoritas yang tidak terlihat. Selama berkomunikasi dengan Allah melalui

29 Sayyid Ahmad Khan, Principles of Exegesis, dalam Aziz. Ahmad dan G.E. Von Grunebaum (eds.), Muslim Self-Statement in India and Pakistan (Weisbaden: Otto Harrassowitz, 1970), 27.

${ }^{30}$ Fazlur Rahman, "Devine Revealation and Prophet," dalam Hamdard Islamicus, vol. 1, no. 2 (1970), 67.

31 Baljon, Religion, 27.

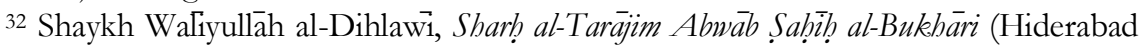
India: Då’irat al-Ma'arif al-'Uthmāniyah, 1982), 2.

33 Ibid. 
malaikat Jibril, Nabi hanyalah sebagai alat atau perantara untuk menyampaikan kehendak-Nya. Dengan demikian, menurutnya Alquran adalah kalam Allah yang qadim yang diturunkan dan diwahyukan dalam bahasa Arab melalui perantara malaikat Jibril dan diceritakan oleh lisan manusia, ditulis di atas salinan-salinan Alquran serta diucapkan oleh kata-kata orang Arab. ${ }^{34}$

Dalam karya yang lain, al-Dihlawi membedakan tiga bentuk evolusi penciptaan Alquran. Pertama, pada tahap awal penciptaan Alquran, firman Allah masuk ke dalam hati Nabi Muhammad. Tahap ini terjadi sebelum periode kenabian. Kedua, pada periode kenabian firman Allah hadir dalam alam imajinatif ('älam al-khayāt) sebagai kata hati (kalam nafs) dan diartikulasikan dengan kata-kata lisan (kalam talaffus). Ketiga, pada tahap ini firman Allah dipadukan dengan pemahaman Nabi Muhammad. Tahap ini terjadi untuk mengembangkan syariat. ${ }^{35}$

Alquran, dalam pandangan al-Dihlawi, memuat lima informasi penting. Pertama, aturan-aturan yang diperlukan dalam praktek-praktek keagamaan, urusan keduniaan, rumah tangga, ekonomi, dan politik. Kedua, polemik yang terjadi antara kaum muslim dengan empat golongan sesat, Yahudi, Nasrani, Musyrik, dan Munafiq. Ketiga, gugahan untuk mengingat anugerah Tuhan dengan menjelaskan bagaimana surga dan dunia diciptakan, dan bahwa dengan berterima kasih dengan cara melaksanakan perintah Tuhan, manusia dapat memenuhi keperluan hidupnya. Keempat, gugahan untuk mengingat hari akhir. Kelima, gugahan untuk mengingat kematian dan hal-hal yang akan terjadi setelahnya pada hari pembangkitan dan perhitungan. ${ }^{36}$

Eksposisi tentang informasi yang terkandung dalam Alquran disajikan dengan gaya penulisan yang digunakan oleh orang Arab masa awal, bukan gaya penulisan orang-orang belakangan. ${ }^{37}$ Ayat-ayat

\footnotetext{
34 Shaykh Waliyullāh al-Dihlawi, Kälimāt al-Ṭayyibät (Delhi: Matba’ Mujtaba’i, 1309 H/1891), 166.

${ }^{35}$ Shaykh Waliyullāh al-Dihlawi, Al-Khayr al-Khatìr (Kairo: Maktabat al-Qāhirah, 1974), 6.

36 Al-Dihlawi, Huijat Allăh al-Bälighah, 55. Tiga yang terakhir dari lima informasi penting dalam Alquran tersebut ada dalam ajaran Nabi Ibrahim, sedangkan empat yang terakhir terdapat dalam ajaran Nabi Musa. Baljon, Religion, 139.

37 Shaykh Waliyullāh, Ahmad bin Abd al-Rahman al-Dihlawi, al-Fauz al-Kabir, terj. Salman al-Husaini an-Nadwi, (Bairut: Dar al-Basya’ir al-Islamiyyah, 1425/2005), 11.
} 
polemik disajikan dengan pembuktian yang populer. ${ }^{38}$ Ayat-ayat yang menggugah untuk mengingat Allah disajikan dengan hal-hal yang diketahui oleh orang banyak. Sifat-sifat Allah disajikan dengan cara yang mudah dipahami. Ayat-ayat tentang kisah-kisah disajikan dengan cara yang dapat mengetuk hati manusia dengan kisah-kisah yang populer di kalangan masyarakat Arab, serta dengan beberapa episod global, sedangkan ayat-ayat tentang kematian disajikan dengan memaparkan kelemahan dan ketidakberdayaan manusia. ${ }^{39}$

\section{Alquran dan Terjemahannya Menurut Shaykh Waliyullāh al- Dihlawi}

Salah satu sumbangan terbesar al-Dihlawi terhadap kajian Alquran adalah terjemahan Alquran ke dalam bahasa Persia, kitab Fath al-Raḅmān bi Tarjamat al-Qur'an. Kitab ini dianggap sebagai kitab terjemah makna Alquran ke dalam bahasa Persia yang paling halus. Menurut alDihlawi, kemampuan menterjemahkan Alquran ke dalam bahasa Persia dengan cara yang menyerupai bahasa Arab dalam kadar kalimat, kekhususan, keumuman, dan lainnya, sebagaimana telah dia gunakan di dalam Fatḥ al-Rahmān bi Tarjamat al-Qur'an, merupakan ilmu pemberian yang dihadirkan oleh Allah pada dirinya, walaupun dia tinggalkan ketentuan tersebut pada sebagian tempat. ${ }^{40}$ Dia mulai menulis kitab tersebut sebelum kepergiannya ke Hijaz untuk menunaikan ibadah haji pada tahun $1143 \mathrm{H}$, kemudian sempat terputus dan baru bisa disempurnakan pada tahun 1151 H. ${ }^{41}$

Kitab Terjemah Alquran ini sebenarnya meliputi dua unsur. Unsur Pertama berupa terjemahan yang tertulis di bawah susunan kalimat Alquran. Unsur Kedua berisi komentar panjang yang dia kaitkan dengan sebagian persoalan yang berhubungan dengan terjemahannya, atau untuk menjelaskan sebagian yang tidak mungkin dimunculkan di dalam terjemahan, akan tetapi dibutuhkan untuk memahami maksud ayat tersebut. Kedua unsur ini dianggap sebagai bagian dari terjemahan Alquran al-Dihlawi, karena pada dua unsur inilah terletak distingsi terjemahan Alquran al-Dihlawi dibanding terjemahan Alquran yang lain.

\footnotetext{
${ }^{38}$ Ibid., 4.

39 Ibid., 11-13.

40 Ibid., 122.

${ }^{41}$ Shaykh Waliyullāh al-Dihlawi, Fath al-Rabmān bi Tarjamat al-Qur'an, (Al-Madinah al-Munawwarah: Majma‘ al-Mulk Fahd li Tabā'ah al-Muṣhaf, 1417 H.), 21-22.
} 
Terdapat beberapa distingsi kitab Fatḥ al-Raḥmān bi Tarjamat alQur'an sebagai terjemahan Alquran dibanding terjemahan Alquran yang lain, antara lain:

a. Terjemahannya termasuk terjemahan yang sangat detail dari makna Alquran ke dalam bahasa Persia. Di dalam penerjemahan, dia memperhatikan makna plural dan singular serta arti subjek dan objek, menjaga makna kondisi dan objek. Dia juga memperhatikan akurasi ungkapan bahasa Arab di dalam terjemahannya sesuai keluasannya. Akan tetapi sebisa mungkin tidak merubah urutan susunan Alquran, kecuali di sebagian tempat yang berupa tarjamah tafsiriyah.

Salah satu contoh dalam menterjemahkan Alquran adalah dalam surah al-Baqarah [2]: 194,

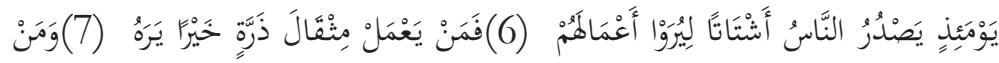

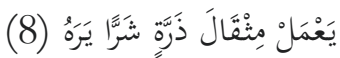

Ayat-ayat tersebut dia terjemahkan dengan bahasa Persia, sebagai berikut:

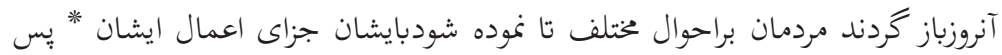

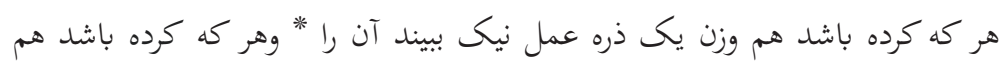

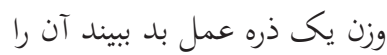

Yang artinya kurang lebih sebagai berikut :

"Pada hari itu, orang-orang akan dibuka kembali dengan cara yang berbeda sehingga dapat dilakukan untuk mereka. Hukuman atas perbuatan mereka. Jadi siapa pun yang melakukannya, biarkan dia melihat beratnya perbuatan baik. Apa pun yang telah dia lakukan, dia akan melihat beratnya partikel tindakan buruk"

Dalam terjemahannya ini, dia menjaga urutan susunan Alquran secara sempurna. Dia terjemahkan tiap kata sesuai urutan susunan Alquran.

b. Menghilangkan kesamaran dengan memperjelas yang diperkirakan di dalam terjemah. Salah satu contoh dalam menterjemahkan Alquran, surah al-Baqarah, ayat 194:

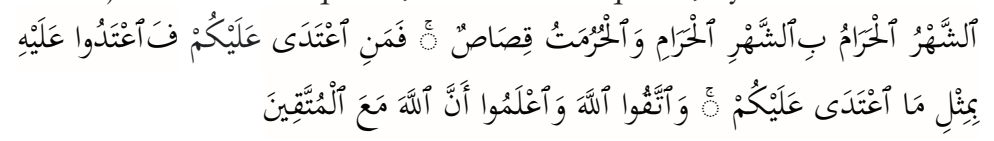

Ayat tersebut dia terjemahkan dengan bahasa Persia, sebagai berikut: 


$$
\begin{aligned}
& \text { اماه حرام عوض ماه حرام است، وحرمت شكنيها داراى قصاص است پِ هر كه }
\end{aligned}
$$

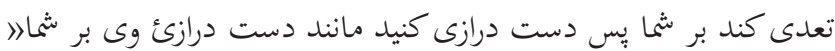

"Bulan suci merupakan pengganti bulan suci. Adapun melakukan pelanggaran di bulan suci mendapat balasan setimpal. Barang siapa yang berbuat melampaui batas pada kalian, maka balaslah dengan balasan yang setimpal."

Di dalan terjemahan ini, dia menampakkan beberapa kata yang diperkirakan ada untuk memahami susunan ayat Alquran, yaitu kata "pengganti" ('iwad) untuk memaknai kata sambung "bi" di dalam ayat "Al-Shahr al-ḩaräm bi al-shahr al-haräm" dengan arti "pengganti" dan berkedudukan sebagai predikat, dan kata "melakukakan pelanggaran" untuk menyempurnakan pemahaman terhadap ayat "wa al-hurumāt qisass", yang berkedudukan sebagai subjek.

c. Memilih beberapa petunjuk gramatika bahasa Arab (Nahwu) di sela-sela terjemah. Terjemahan al-Dihlawi menjadi istimewa dengan menyelesaikan problematika gramatika bahasa (Nahwu dan I'rab) lalu memilih yang lebih mendekati kebenaran gramatika bahasa Arab pada masa turunnya Alquran. Salah satu contoh dalam menterjemahkan Alquran, surah at-Taubah, ayat 19:

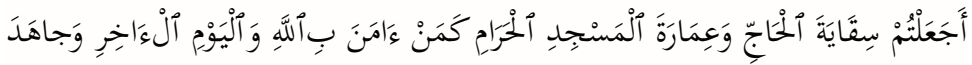

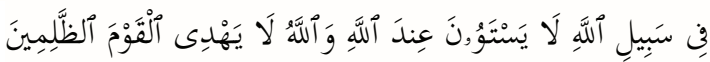

Ayat tersebut dia terjemahkan dengan bahasa Persia, sebagai berikut:

$$
\begin{aligned}
& \text { اآيا كرديد آب نوشانيدن حاجيان را وآباد ساختن مسجد حرام را ماند عمل كسى } \\
& \text { كه ايمان آورده است بخدا وروز آخرت وجهاد كرده است در راه خدالا إنال }
\end{aligned}
$$

"Apakah (orang-orang) yang memberi minuman orang-orang yang mengerjakan haji dan mengurus Masjidil haram kamu samakan dengan perbuatan orang-orang yang beriman kepada Allah dan hari kemudian serta bejihad di jalan Allah? Mereka tidak sama di sisi Allah; dan Allah tidak memberi petunjuk kepada kaum yang zalim."

Di dalam terjemahan ini, dia memilih menambahkan kata "perbuatan" ('amal) dalam ayat "ka man amana billäh wa alyawm al-äkhir" untuk memparalelkan kepatutan penyamaan suatu peristiwa dengan suatu peristiwa dan penyamaan suatu 
dengan suatu benda, bukan penyamaan suatu perbuatan dengan sutu benda atau sebaliknya.

\section{Pemahaman dan Penafsiran Yang Baik Terhadap Alquran}

Menurut al-Dihlawi, kesulitan dalam memahami Alquran dikarenakan adanya lafal-lafal yang asing, adanya penghapusan satu ayat dengan ayat yang lain, adanya sebab-sebab turunnya ayat, dan susunan kalimat yang sulit.42 Oleh karena itu, agar dapat memahami Alquran dengan baik, al-Dihlawi menawarkan beberapa prinsip yang harus dipegang. Pertama, menguasai bahasa Arab, memiliki pengetahuan yang memadai tentang lafal-lafal asing yang terdapat dalam Alquran dan tentang persoalan di sekitar al-naskh

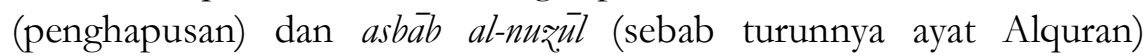
dengan merujuk kepada hadis-hadis Nabi. ${ }^{43}$ Kedua, mengetahui situasi politik, situasi sosio-kultural, dan situasi keagamaan masyarakat ketika Alquran diturunkan. ${ }^{44}$ Ketiga, ketentuan-ketentuan dalam Alquran harus dipahami sebagai sesuatu yang universal dan relevan sepanjang masa. ${ }^{45}$ Keempat, kisah-kisah dalam Alquran harus dipahami sebagai bertujuan untuk menggugah hati pembaca dan pendengarnya agar dapat mengambil pelajaran darinya, bukan untuk mengetahui kisah itu semata. ${ }^{46}$ Kelima, bahasa yang digunakan Alquran adalah bahasa Arab yang digunakan oleh generasi pertama Islam yang gramatika dan sastranya mengikuti gramatika dan sastra yang dikenal oleh kebanyakan orang Arab masa itu. ${ }^{47}$

Dari prinsip-prinsip tersebut dapat dipahami bahwa meskipun dalam mendapatkan pemahaman ataupun penafsiran yang baik diharuskan mempunyai kemampuan bahasa Arab yang memadai, namun bahasa dengan gramatika, gaya bahasa, dan sastra yang dikenal oleh kebanyakan orang di kala Alquran turun, bukan bahasa Arab dengan persoalan-persoalannya yang detail dan rumit menurut pakar bahasa Arab. Di samping itu, al-Dihlawi juga menyumbangkan gagasan-gagasan baru di sekitar persoalan asbāb al-nuгūl, al-naskh, kisah-kisah isrä'iliyat yang menyusup ke dalam karya-karya tafsir

\footnotetext{
42 Ibid., 5.

${ }^{43}$ Al-Dihlawi, Huijat Allāh al-Bälighah, 72.

44 Al-Dihlawi, Al-Fawz, 5.

45 Ibid., 11.

46 Ibid., 3.

${ }^{47}$ Ibid., 38.
} 
Alquran. Di era klasik dan pertengahan, ketiga persoalan tersebut sempat menjadi perdebatan yang hangat, karena ketiganya sangat menentukan pemahaman dan penafsiran Alquran. Oleh karena itu, secara kritis al-Dihlawi melihat kembali perdebatan-perdebatan tersebut untuk kemudian memuncukan gagasan-gagasan baru yang sesuai dengan masanya.

Bagi al-Dihlawi, asbāb al-nuzū sangat penting peranannya dalam membantu memahami dan menafsirkan Alquran, namun demikian dia tidak mempercayai sebagian besar kisah-kisah yang diriwayatkan dan diklaim sebagai asbāb al-nu₹̄ul, sehingga tidak harus diketahui oleh seorang mufasir. ${ }^{48}$ Dalam penelitiannya terhadap riwayat-riwayat dari sahabat dan tabiin, al-Dihlawi menemukan bahwa perkataan "nuશilat fi kadza" yang sering digunakan dalam meriwayat suatu kisah yang oleh banyak orang dianggap sebagai asbāb al-nuzūl, sebenarnya tidak semata-mata untuk menunjuk bahwa kisah tersebut adalah asbāb alnuгūl, melainkan seringkali yang dimaksudkan adalah menujuk bahwa kisah atau peristiwa itu merupakan sebagian dari apa yang dimaksudkan oleh satu ayat. ${ }^{49}$

Kisah-kisah dalam hadis, misalnya, yang inti pokok tujuannya sejalan dengan suatu ayat menentukan tempat turunnya ayat, atau menentukan nama orang yang disebut secara samar dalam Alquran. Hal itu, menurut al-Dihlawi, pada hakekatnya bukan asbāb al-nu₹̄il, sehingga tidak harus diketahui oleh seorang mufassir, yaitu kisah-kisah yang memang disinggung dalam ayat-ayat Alquran dan kisah-kisah yang berfungsi untuk memalingkan kata dari arti literalnya, baik sebagai takhsis atau yang lainnya, yang sekiranya suatu ayat tidak mudah dipahami tanpa mengetahui kisah-kisah tersebut. ${ }^{50}$

Dalam perspektif al-Dihlawi, asbāb al-nuzū harus logis dan harus dikaitkan dengan tujuan pokok dan pengetahuan yang terkandung dalam Alquran, yaitu mendidik jiwa, menghancurkan keyakinankeyakinan yang sesat, dan membasmi perbuatan dan tingkah laku yang merusak. Dengan demikian menurutnya, asbāb al-nuұ̄ul dari ayat-ayat mukhasamah (permusuhan) adalah keyakinan-keyakinan batil yang dianut oleh orang-orang pada masa turunnya ayat-ayat tersebut. $A s b \bar{a} b$ al-nu₹̄ul dari ayat-ayat hukum adalah adanya perbuatan yang merusak

\footnotetext{
${ }^{48}$ Ibid., 21.

${ }^{49}$ Ibid., 25.

${ }^{50}$ Ibid., 34-35.
} 
dan berlangsungnya kezaliman di tengah-tengah mereka. Asbāb alnигul dari ayat-ayat tadhkir (pengingat) adalah ketidaksadaran mereka untuk mengingat nikmat-nikmat Allah, peristiwa-peristiwa yang terjadi pada berbagai umat terdahulu, dan seluk-beluk kematian dengan segala kelanjutannya. ${ }^{51}$ Namun sayang dalam karya-karyanya yang sempat penulis baca, al-Dihlawi tidak memberikan contoh yang kongkrit atas konsep-konsepnya tersebut. Walaupun demikian, kalau dicermati lebih mendalam akan tampak bahwa dia sangat menekankan kepada para mufasir Alquran dalam mencari asbāb al-nu₹ū suatu ayat Alquran untuk tidak terjebak pada riwayat-riwayat belaka, melainkan lebih dari itu, harus melihat bagaimana situasi dan kondisi sosial, budaya, politik, agama, ekonomi, dan psikologi masyarakat pada waktu Alquran diturunkan.

Konsep asbāb al-nu₹̄ul al-Dihlawi tersebut di atas, di samping sebagai konsep baru yang membawanya pada konteks yang jauh lebih luas daripada yang selama ini dipahami, juga mengisyaratkan arti pentingnya pengetahuan akan konteks sosial, politik, keagamaan masyarakat pada masa Alquran diturunkan. Di kemudian hari, pentingnya pengetahuan tersebut ditangkap oleh 'Abduh. Dia menyebutnya sebagai pengetahuan tentang pengambilan hidayah Alquran oleh masyarakat manusia seluruhnya.

Meskipun asbāb al-nu₹̄il sangat penting dalam pandangan alDihlawi, akan tetapi nilai-nilai universal dari ayat-ayat Alquran dinilai jauh lebih penting. Dalam kupasannya mengenai pola polemik Alquran menghadapi empat golongan yang tersesat, yaitu Yahudi, Nasrani, kaum musyrik, dan munafik, misalnya, al-Dihlawi berulangkali menegaskan bahwa setiap ciri dari manusia yang disebut dalam Alquran tidak boleh diartikan secara terbatas hanya pada golongan dan bangsa yang disebut secara nyata, melainkan harus dipahami secara universal dan eternal, sebab ciri-ciri tertentu dari manusia di masa lalu pasti akan dijumpai di setiap masa dan tempat. ${ }^{52}$

Persoalan berikutnya yang mempengaruhi pemahaman dan penafsiran Alquran adalah perdebatan di sekitar al-naskh. Bertolak dari teori sosial ${ }^{53}$ dan teori syariat yang dikemukakannya, ${ }^{54}$ al-Dihlawi

\footnotetext{
51 Ibid.

52 Ibid., 43.

${ }^{53}$ Gagasan al-Dihlawi tentang evolusi kehidupan sosial bisa dibaca di dalam Baljon, Religion, 192-199.
} 
menegaskan bahwa terjadinya al-naskh dalam syariat Nabi Muhammad adalah sesuatu yang wajar, bahkan untuk mendapatkan penafsiran yang baik, dia mengharuskan seorang penafsir mengetahui perdebatan di sekitar al-naskh. 55 Akan tetapi, al-Dahlawi hanya memegangi konsep al-naskh yang ada pada sahabat dan tabiin. ${ }^{56}$ Dari sini, kemudian alDihlawi menjelaskan bahwa pegangan pokok dalam menjelaskan alnaskh adalah sejarah, bukan konsesnsus ulama sebagaimana yang sering digunakan. Gagasan tersebut mengantarkannya untuk sampai pada kesimpulan bahwa ayat yang mansükh ada lima.57 Di abad ke-20, pengaruh pemikiran al-Dihlawi terlihat dalam pemikiran Muhammad Zayd yang menemukan enam ayat yang di-mansūk $h^{58}$ dan Subḥi Ṣălih yang menemukan sepuluh ayat yang di-mansükh. 59

Demikian juga dengan kisah isra'tiliyat sebagai kisah yang bersumber dari luar Islam, baik Yahudi, Nasrani maupun yang lainnya, telah ikut menghiasi lembaran-lembaran karya tafsir Alquran. Penelitian al-Dhahabi menemukan bahwa tidak ada satu karya tafsir pun yang di dalamnya tanpa sisipan kisah isräitiyat. Sudah barang tentu hal ini telah menimbulkan ekses negatif bagi pola keberagamaan dan pola berpikir umat Islam. Hal ini memerlukan penyikapan yang arif.

Nabi Muhammad telah memberikan pedoman dalam menyikapi kisah-kisah isra'iliyyat melalui dua sabdanya:

$$
\begin{aligned}
& \text { 1. بلغوا عني ولو اية وحدثوا عن بني اسرائل ولا حرج ومن كذب علي متعمدا } \\
& \text { فليتبواء مقعده من النار } \\
& \text { 2. لا تصدقوا اهل الكتاب ولا تكذوبهم وقولوا أمنا بالله وما انزل الينا وما انزل اليكم ملئم }
\end{aligned}
$$

\footnotetext{
${ }^{54}$ Gagasan al-Dihlawi tentang evolusi syariah bisa dibaca di dalam al-Dihlawi, Hujjat Allăh, vol. 1, 172. Bandingkan dengan Mukti Ali yang menganggap 'Abduh sebagai orang pertama yang mengumandangkan teori evolusi syariah. Mukti Ali, Ilmu Perbandingan Agama (Yogyakarta: Nida, 1975), 27.

55 Ibid.

56 Al-Dihlawi, Al-Fawr, 16.

57 Ibid. lihat juga, Moh Abdul Kholiq Hasan, "Ayat-ayat Kebebasan Beragama dalam Perspektif Nasakh: Kajian Terhadap Penafsiran Ibn Kathir dan Rashid Rida," dalam Mutawatir Jurnal Kielmuan Tafsir Hadith, vol. 6, no. 2 (2016).

58 Mustafa Zayd, Al-Naskh fi Al-Qur'an al-Karim: Dirasät Tashrīiyah Tankhiyyah Naqdiyya (Bairut: Dār al-Fikr, 1971), 106-110.

${ }^{59}$ Șubḥi Șălih, Mabāhịth fì 'Ulùm Al-Qur'àn (Bairut: Dār al-'Ilm al-Malāyin, 1977), 274.
} 
Hingga masa sahabat, kedua petunjuk Nabi tersebut dengan penuh kehati-hatian dipegangi oleh para mufasir pada waktu itu. Akan tetapi, ketika memasuki masa tabiin dan generasi sesudahnya, kisahkisah isräiliyat menjadi semakin meluas di dunia Islam dikarenakan semakin banyaknya non-muslim yang masuk Islam, terutama dalam wilayah penafsiran Alquran yang tidak dikontrol lagi.

Dalam kondisi semacam itu, al-Dihlawi bermaksud menghidupkan kembali pedoman yang diajarkan Nabi Muhammad yang telah banyak dilupakan tersebut. Dia mengemukakan dua sikap terhadap kisah isra'iliy at. Pertama, penukilan dari sumber ahli kitab tidak perlu jika hadis Nabi telah menjelaskan apa yang disinggung oleh Alquran. Kedua, jika penukilan itu terpaksa harus dilakukan, maka harus dilakukan sekedar sebagai usaha mencari kejelasan tentang apa yang disinggumg oleh Alquran. ${ }^{60}$ Jadi al-Dihlawi tidak menolaknya secara total, kendati sebagai bentuk penyusupan ajaran dari luar Islam.

\section{Kesimpulan}

Dari paparan dan pembahasan di atas, dapat disimpulkan bahwa Shaykh WaTiyullāh al-Dihlawi adalah pembaharu pemikiran Islam pada abad modern dalam Islam, terutama di India. Dalam mengembangkan pemahaman terhadap fiqih, tasawuf dan Alquran, dia mengedepankan metode rekonsiliasi yang dinilainya dapat menjadi alternatif pemikiran yang dapat mengatasi berbagai perbedaan. Penerapan metode tersebut dapat di lihat, misalnya, dalam ketidak senangannya terhadap fanatisme atas satu mazhab. Akan tetapi, alDihlawi menempatkan berbagai mazhab fikih secara dialektis, sehingga dapat meredam berbagai ketegangan. Demikian juga dalam bidang tasawuf, dia menempatkan wahdat al-shubüd sejajar dengan paham waḥdat al-wujü. Keduanya sama-sama diakui oleh al-Dihlawi.

Sebagai akibat dari penerapan metodenya tersebut, nuansa rasionalitas terasa sangat kental dalam pemikiran al-Dihlawi, karena dia selalu mengkaji dan mempertimbangkan berbagai konsep dan pendapat yang ada, yang kemudian darinya muncul gagasan-gagasan baru. Oleh karena itu, al-Dihlawi sangat mengecam taklid buta, yang dinilainya hanya akan menimbulkan kemunduran dunia Islam.

Corak pemikiran rasional al-Dihlawi juga bisa dilihat dalam gagasan-gagasan barunya tentang Alquran. Pemikiran rasionalnya

${ }^{60}$ Al-Dihlawi, Al-Faw: 37. 
terlihat dalam gagasannya tentang asal usul Alquran, dalam ke-qadiman Alquran, dalam teori evolusi penciptaannya, dan dalam informasiinformasi yang terkandung dalam Alquran itu sendiri. Corak rasionalitas pemikirannya juga dapat dijumpai dalam gagasan barunya tentang asbāb al-nu₹ūl, al-naskh, dan analisisnya terhadap kisah-kisah isra'iliyat. Sedangkan gagasan baru al-Dihlawi tentang pemahaman dan penafsiran yang baik terhadap Alquran terletak pada lima prinsip memahami dan menafsirkan yang baik terhadap Alquran yang digagasnya, yang meliputi: 1) Penguasaan terhadap bahasa Arab dengan segala dimensinya; 2) Pemahaman terhadap situasi politik, situasi sosio-kultural, dan situasi keagamaan masyarakat ketika Alquran diturunkan; 3) Pemahaman terhadap ketentuan-ketentuan dalam Alquran sebagai sesuatu yang universal dan berlaku sepanjang masa; 4) Pemahaman terhadap kisah-kisah dalam Alquran sebagai sesuatu yang harus diambil pelajaran darinya, bukan mengetahui kisah itu semata; 5) Penggunaan bahasa Arab yang digunakan Alquran, yaitu bahasa Arab dengan gramatika dan sastra yang dikenal oleh orang Arab ketika Alquran turun.

\section{Daftar Pustaka}

Ahmad, Aziz. Studies in Islamic Culture in The Indian Environment. Oxford: Oxford Univerdity Press, 1966.

Ali, Mukti. Ilmu Perbandingan Agama. Yogyakarta: Nida, 1975.

Anshari (al), Abd. Al-Haq. Shaykh Waliyullah Attemps to Revise Waḅdah al-Wujüd, t.t. : 1988.

Azra, Azyumardi. Jaringan Ulama' Timur Tengah dan Kepulauan Nusantara, Mencari Akar-akar Pembaharuan Pemikiran Islam di Indonesia. Bandung: Mizan, 1995.

Baljon, J.M.S. Modern Muslim Koran Interpretation (1880-1960). Leiden: E.J. Brill, 1963.

Religion and Thoutght of Shaykh Waliyulläh al-Diblawì. Leiden: E.J. Brill, 1963.

Dihlawi (al), Shaykh Waliyullāh. Sharḅ al-Taräim Abwāb Sahạị̧ alBukhäri. Hiderabad India: Dā'irah al-Ma'arif al-'Uthmāniyah, 1982.

- Kälimät al-Tayyibät dalam Collection of Persian Letters.

Delhi: Matba‘ Mujtaba'i, 1309 H/1891. . Al-Khayr al-Khatìr. Kairo: Maktabat al-Qāhirah, 1974. 
Fāḍil (al), Al-Sayyid Murtaḍa Ḥusayn al-Ṣadr. "Beberapa Metodologi Tafsir Alquran di Anak Benua India," terj. Husain al-Kaff. Jurnal al-Hikmah, vol. VI, no. XIV (1995).

Hasan, Moh Abdul Kholiq. "Ayat-ayat Kebebasan Beragama dalam Perspektif Nasakh: Kajian Terhadap Penafsiran Ibn Kathir dan Rashid Rida." Mutawatir Jurnal Kielmuan Tafsir Hadith, vol. 6, no. 2 (2016).

Hermansen, Marcea K. Shaykh Waliyullāh of Delhi's al-Hujjatullāh alBälighah. Leiden: E.J. Brill, 1886.

Iqbal, M. The Recontruction of Religious Thought in Islam. Lahore: Shaykh M. Ashraf, 1962.

Jameelah, Maryam. Islam in Theory and Paractice. Delhi: Taj Company, 1983.

Jalbani, G.N. Life of Shaykh W aliyulläh. Delhi: Idarah-1 Delli, 1980.

Khan, Sayyid Ahmad. "Principles of Exegesis." Muslim Self-Statement in India and Pakistan. Diedit oleh Aziz. Ahmad dan G.E. Von Grunebaum. Weisbaden: Otto Harrassowitz, 1970.

Mahmasani, Subhi. Tadbkirat min Mälik al-Sunbin. Bairut: Dār al-'Ilm al-Malāyin, 1979.

Rahman, Fazlur. "Devine Revealation and Prophet." Hamdard Islamicus, vol. 1, no. 2 (1970).

Șalih, Șubḥi. Mabāhith fì 'Ulum Al-Qur'àn. Beirut: Dār al-'Ilm alMalayin, 1977.

Smith, W.C. Islam ini Modern History. New York: Princeton University Press, 1957.

Zayd, Muștafa. Al-Naskh fì Al-Qur'an al-Karim: Diräat Tashri'īyah Tankhìyah Naqdìyah. Beirut: Dār al-Fikr, 1971. 